\title{
Um Estudo Sobre os Diferenciais de Remuneração Entre os Professores das Redes Pública e Privada de Ensino
}

\author{
- Fernando de holanda barbosa Filho* - Samuel de Abreu Pessôa ** \\ - Luís EduARDo AFOnSO ***
}

\begin{abstract}
RESUMO
O artigo investiga os diferenciais de remuneração entre os professores dos diversos níveis de ensino, das redes pública e privada. Analisando somente os salários, os diferenciais são na maior parte dos casos favoráveis ao setor privado. Esta conclusão se altera quando se calcula o Valor Presente do Contrato de Trabalho. O VPCT leva em consideração toda a renda auferida pelo docente, incluindo os salários recebidos durante a vida ativa e também a aposentadoria. O VPCT do ensino público é sempre mais elevado que o VPCT privado. Também são calculadas as Taxas Internas de Retorno (TIRs) da previdência social, cujos resultados mostram que os retornos do setor público são maiores que os do setor privado. Conclui-se que as diferentes regras de aposentadoria têm importância significativa nos rendimentos ao longo da vida dos docentes. Também se conclui que docentes da rede pública não recebem remuneração inferior a seus pares do setor privado.
\end{abstract}

\section{ABSTRACT}

This paper studies the earnings differentials between public and private professors in the different levels of education. In most of the cases, there is a positive differential in favor of the private sector. This conclusion changes when we compute the Present Value of the Work Contract (PVWC). The PVWC considers all the income received during the workers life span. Here, we compute the present value of the wages received in the working life with the retirement benefits. The results show that the PVCW is higher in the public sector than in the private sector. We compute the internal rate of return (IRR) of the retirement system. We conclude that different retirement rules between the two sectors have a huge impact in the professors' life earnings with a public IRR higher than the private one. We also conclude that public teachers do not receive lower earnings than their private counterparts.

\section{Palavras-Chave}

diferenciais de remuneração, salários, professores, contrato de trabalho, setor público

\section{KEYWORDS}

wage differentials, wages, teachers, labor contract, public sector

\section{JEL ClASSIFICATION}

I2I, J3I, J44

\footnotetext{
* Professor da FGV e pesquisador do Centro de Crescimento Econômico do Instituto Brasileiro de Economia (IBREFGV). Endereço para contato: Rua Barão de Itambi, 60 - $8^{\circ}$ andar. CEP 22231-000. E-mail: fhbf@fgv.br.

** Professor da FGV e pesquisador do Centro de Crescimento Econômico do Instituto Brasileiro de Economia (IBREFGV). Endereço para contato: Rua Barão de Itambi, 60 - $8^{\circ}$ andar. CEP 2223I-000. E-mail: pessoa@fgv.br.

$\star \star \star$ Professor do Departamento de Contabilidade e Atuária da FEA/USP. Endereço para contato: Av. Prof. Luciano Gualberto, 908 - Prédio FEA 3 - sala 215. CEP 05508-900. E-mail: lafonso@usp.br.

(Recebido em novembro de 2007. Aceito para publicação em setembro de 2008).
} 


\section{$1 \quad$ INTRODUÇÃO ${ }^{1}$}

A educação ganhou no último decênio no Brasil o destaque que este tema merece, pela sua importância no desenvolvimento econômico e social de um país. Esforços de grande monta têm sido feitos para identificar e avaliar os fatores que possam influenciar o processo educacional. Paralelamente a esses esforços, uma noção permeia o senso comum. Alguns formadores de opinião e educadores argumentam que a principal causa dos melhores resultados obtidos pelos alunos das escolas privadas em testes de avaliação é o diferencial de remuneração dos docentes. A rede pública pagaria baixos salários comparativamente à rede privada. Isso implicaria ensino de pior qualidade,$^{2}$ o que seria a causa dos maus resultados dos alunos das escolas públicas. Será esse argumento correto?

O caminho para confirmar (ou negar) o argumento é verificar empiricamente se os professores da rede pública de ensino recebem salários inferiores àqueles pagos na rede privada. Esses são os objetivos desse trabalho: inicialmente, analisar os salários brutos pagos pelas redes pública e privada e quantificar o diferencial entre elas. Em seguida, de forma inovadora, calcula-se o Valor Presente do Contrato de Trabalho (VPCT) dos professores das duas redes. Posteriormente, calcula-se a TIR dos sistemas de previdência público e privado. Em todos os casos os dados analisados referem-se aos diversos níveis de ensino: pré-escola, fundamental, médio, profissional e superior.

O trabalho encontra-se organizado da seguinte forma: na próxima seção encontrase um breve resumo da literatura. Na seção 3 é exposta a metodologia empregada. A seção 4 mostra o perfil dos salários ao longo do ciclo de vida dos professores. Os diferenciais de salários para os diversos níveis de ensino são apresentados na seção 5 . Na seção 6, os resultados são analisados para cada nível de ensino para os Estados. O cálculo e a análise comparativas dos VPCTs nas redes de ensino pública e privada, nos diversos níveis de ensino são realizados na seção 7 . Na seção 8 é apresentada uma outra forma de avaliação dos diferenciais, por meio do cálculo das TIRs. Finalizando, na seção 9 apresentam-se os comentários finais.

1 Os autores gostariam de agradecer os comentários de um parecerista anônimo. Como de praxe, toda responsabilidade pela versão final do texto é dos autores.

2 A qualidade da educação parece depender de um extenso conjunto de determinantes. Alguns deles são o tempo letivo, a qualificação do professor, as instalações da escola e o tamanho da turma. Um resumo sobre esses determinantes pode ser encontrado em Gomes (2005). 
O estudo do diferencial de remuneração público/privado é um assunto bastante estudado na literatura internacional. Há vários trabalhos sobre este tema. Entretanto, a literatura nacional ${ }^{3}$ de caráter empírico, sobre o diferencial público-privado, particularmente dos profissionais de educação, é relativamente restrita e pouco conclusiva.

Katz e Krueger (1991) mostram que trabalhadores menos qualificados obtiveram um prêmio crescente de salário no setor público norte-americano durante os anos 80. No mesmo período, observou-se uma redução do prêmio pago ao trabalhadores mais qualificados. Ao fazer uma resenha sobre os trabalhos de Ehrenberg e Schwarz (1986) e Gregory e Borland (1999), Ehrenberg e Smith (1994) concluem que existe um prêmio salarial para mulheres no setor público norte-americano e uma perda relativa para homens.

Poterba e Rueben (1998) investigam as mudanças de salários relativos entre os setores público e privado no período 1979-1986. Os autores concluem que houve um crescimento maior dos salários de trabalhadores na iniciativa privada do que no setor público. Borjas (2005) analisa o diferencial público/privado entre 1960 e 2000. O autor mostra que o diferencial permaneceu praticamente constante para os homens, mas caiu bastante para mulheres. A compressão salarial dos servidores públicos americanos após a década de 70 é importante na escolha do setor por parte do trabalhador. Por esse motivo, o setor público dos EUA tem dificuldade para atrair trabalhadores qualificados.

Para o Brasil, Ramalho e Urani (1995) mostram que a parcela de empregados da administração pública cresceu durante a década de 80 , passando de $11 \%$ da PEA em 1981 para 12,5\% em 1990. Os autores mostram, ainda, que os servidores públicos recebem em média $45 \%$ mais que os trabalhadores da iniciativa privada. Entretanto, controlando-se tal diferencial por características observáveis, o diferencial públicoprivado passa a ser negativamente correlacionado com a qualificação do trabalhador, sendo positivo para os trabalhadores com pouca instrução e negativo para os mais instruídos.

Além disso, Pastoriza e Giambiagi (1998) analisam o subsídio implícito obtido pelos professores, por terem regras de aposentadoria diferenciadas. Os autores mostram que as professoras são extremamente beneficiadas por esse privilégio. Foguel et alii (2000) encontram diferenciais salariais positivos para o setor público. Parte do diferencial é devida às características observáveis dos indivíduos. Eles mostram que o

3 Para uma precisa resenha dos aspectos teóricos sobre desigualdade salarial, ver Fernandes (2002). Para trabalho análogo, sobre os trabalhos de cunho empírico para o Brasil, ver Coelho (2002) 
diferencial depende da esfera pública de atuação, sendo positivo nas esferas federais e estaduais, e negativo na municipal.

Marconi (2004) trata da remuneração dos setores público e privado durante os anos 1990. Sua primeira conclusão é a existência de segmentação no mercado de trabalho, visto que trabalhadores com características similares são mais bem remunerados no setor público. Este diferencial não é uniforme, sendo inversamente proporcional à qualificação do trabalhador. Sua segunda conclusão é que o setor público, por sua própria natureza, tem regras peculiares de formação de salário. Desta maneira, questões como o peso dos funcionários públicos nos mercados de trabalho locais, bem como a relevância das transferências governamentais são fatores importantes na explicação dos diferenciais encontrados. Trabalho com motivação próxima é feito por Bender e Fernandes (2006), que estudam, empregando as PNADs e 1992 a 2004, diversos aspectos do setor público no Brasil. No período analisado, o hiato educacional da qualidade do trabalhador público em relação ao privado diminuiu. Os autores constatam, também, um crescimento do diferencial de salários em favor do setor público. Para Arvate et alii (2006) existe um diferencial favorável ao funcionário público. De forma similar a Foguel (2000) encontra-se grande heterogeneidade nas políticas salariais entre os entes federativos. Finalmente, Moriconi (2007), analisando dados dos Estados brasileiros extraídos do Censo de 2000, encontra evidências pouco conclusivas sobre o diferencial público-privado.

Um ponto comum aos estudos listados é que todos analisam os diferenciais públicoprivado por meio da comparação da remuneração auferida apenas durante o período ativo dos trabalhadores, ou seja, os salários. Como será apresentado na seção 7 , propõe-se neste trabalho uma forma alternativa de quantificação dos diferenciais englobando também o período de inatividade dos indivíduos, no qual há o recebimento da aposentadoria. Esta escolha metodológica justifica-se pelas características do sistema previdenciário brasileiro. Membros de uma mesma coorte podem estar sujeitos a regras previdenciárias distintas, tanto no tocante às condições de elegibilidade e de cálculo dos benefícios, quanto às contribuições. Essas diferenças são particularmente relevantes quando se comparam trabalhadores de uma mesma ocupação (no caso os docentes) dos setores público e privado. 


\subsection{Base de dados}

Para estudar o diferencial de salário público/privado foram utilizados os Censos Demográficos realizados pelo IBGE nos anos 1980, 1991 e 2000. Esse conjunto de dados apresenta, para cada ano, mais de 20 milhões de observações. Cada célula do banco de dados representa um indivíduo. Assim sendo, cada célula apresenta diversas características como idade, atividade de atuação, salário e horas trabalhadas. Esse grande volume de dados é necessário devido ao escopo desse trabalho, no qual se foca em um pequeno grupo, formado por professores que atuam nas áreas privada $\mathrm{e}$ pública. Além disso, como é feita uma análise para diferentes Estados, se fosse empregada uma pesquisa amostral, como a PNAD, o conjunto de dados seria bastante reduzido, dificultando a análise dos dados para algumas unidades da Federação devido ao baixo número de observações, o que geraria confiabilidade reduzida.

\subsection{Metodologia do cálculo dos salários}

Para obter os diferenciais de salário entre os professores das redes pública e privada, o primeiro passo é o cálculo dos salários médios. O salário médio $w_{j k}$ é dado pela equação l:

$$
w_{j k}=\sum_{i=1}^{N} \frac{p_{i} w_{i} d_{j} v_{k}}{p_{i} d_{j} v_{k}}
$$

Na equação $1, w_{j k}$ é o salário médio pago na rede de ensino $j$ (privada ou pública) e no nível $k$ (pré-escola, fundamental, médio, profissional ou superior). $\mathrm{O}$ termo $p_{i}$ é o peso da observação $i ; w_{i}$ é o salário recebido pelo indivíduo $i ; d_{j}$ é uma variável dummy igual a $l$ se o indivíduo atua na rede $j$, e zero caso contrário, e $v_{k}$ é uma outra variável dummy para cada um dos cinco níveis de ensino.

Uma vez obtidos os salários médios, para cada nível de ensino calcula-se o diferencial público-privado $D i f_{k}$ como a razão entre os salários médios, da forma dada pela equação 2. O termo $k$ é o nível de ensino, pub a rede pública e priv a rede privada.

$$
\operatorname{Dif}_{k}=\frac{w_{p u b, k}}{w_{p r i v, k}}
$$




\section{DADOS DE REMUNERAÇÃO}

\subsection{Perfis salariais: Brasil}

O primeiro passo é verificar os salários médios recebidos pelos professores. Esta análise permite ter uma ideia da evolução dos salários na carreira de professor. Nesta subseção são apresentados os salários médios para o Brasil como um todo. Os dados podem ser vistos na Tabela $1 .{ }^{4}$ Há 10 coortes. Na primeira estão incluídos os profissionais de 20 a 24 anos; na segunda, estão incluídos aqueles com 25 a 29 anos e assim sucessivamente. Os dados, oriundos do Censo de 2000, mostram que, de forma geral (e consistente com as evidências da literatura) os salários pagos crescem ao longo da carreira. Um ponto comum entre os setores público e privado é a redução nas taxas de crescimento salarial ao longo do ciclo de vida.

TABELA I- PERFIL SALARIAL DOS PROFESSORES DO BRASIL POR COORTE E REDE DE ENSINO (VALORES EM R\$/MÊS - SET./2000)

\begin{tabular}{|c|c|c|c|c|c|c|c|c|c|c|}
\hline \multicolumn{11}{|c|}{ Coorte (Idade) } \\
\hline & $20-24$ & $25-29$ & $30-34$ & $35-39$ & $40-44$ & $45-49$ & $50-54$ & $55-59$ & $60-64$ & $>65$ \\
\hline \multicolumn{11}{|c|}{ Pré-escola } \\
\hline Público & 258 & 350 & 415 & 464 & 499 & 524 & 552 & 653 & 515 & 262 \\
\hline Privado & 292 & 392 & 467 & 538 & 526 & 597 & 581 & 468 & 961 & 407 \\
\hline \multicolumn{11}{|c|}{ Fundamental - Primário } \\
\hline Público & 450 & 656 & 771 & 848 & 902 & 984 & 986 & 1006 & 1042 & 951 \\
\hline Privado & 480 & 668 & 827 & 935 & 983 & 1073 & 1084 & 1092 & 1114 & 1188 \\
\hline \multicolumn{11}{|c|}{ Fundamental - Ginásio } \\
\hline Público & 295 & 384 & 457 & 494 & 550 & 608 & 634 & 633 & 597 & 636 \\
\hline Privado & 321 & 411 & 488 & 544 & 629 & 655 & 691 & 738 & 657 & 737 \\
\hline \multicolumn{11}{|c|}{ Médio } \\
\hline Público & 482 & 759 & 906 & 1002 & 1092 & 1196 & 1233 & 1226 & 1322 & 1507 \\
\hline Privado & 560 & 876 & 1085 & 1184 & 1280 & 1374 & 1394 & 1416 & 1549 & 1403 \\
\hline \multicolumn{11}{|c|}{ Superior } \\
\hline Público & 734 & 1562 & 2155 & 2584 & 2963 & 3347 & 3479 & 3880 & 3551 & 3792 \\
\hline Privado & 988 & 1732 & 2151 & 2572 & 3001 & 3060 & 3128 & 3394 & 3584 & 3383 \\
\hline
\end{tabular}

4 Os níveis primário e ginásio estão englobados no ensino fundamental. No texto, os termos primário e ginásio referem-se, respectivamente, à $1^{\mathrm{a}}$ a $4^{\mathrm{a}}$ séries, e à $5^{\mathrm{a}}$ a $8^{\mathrm{a}}$ séries do ensino fundamental. 
O perfil salarial na pré-escola mostra que o salário da rede privada é sempre superior ao da rede pública. Entretanto, esta diferença é pequena, da ordem de 10\%. Quando são comparados os salários dos professores primários das redes pública e privada observa-se que os salários no início de carreira são similares. Entretanto, a partir dos 30 anos de idade, a iniciativa privada passa a pagar um pequeno prêmio de salário, na casa dos $10 \%$. A mesma análise é válida para os professores do ginásio.

No ensino médio, o diferencial salarial em favor do professor da rede privada de ensino atinge seus níveis mais elevados, sendo superior à média de $10 \%$. Este diferencial parece corroborar a evidência de que no ensino médio há carência de professores na rede pública, fato este que sinaliza a existência deste maior diferencial. ${ }^{5}$ Os professores do ensino superior recebem um salário médio igual ao pago na rede privada até a faixa de 40 a 44 anos. Para as coortes mais velhas, os professores do ensino superior público passam a receber um salário superior ao pago na rede privada. Esta tendência só se altera a partir dos 60 anos. Esta inversão é muito provavelmente fruto de autosseleção, uma vez que somente os professores com maiores salários permanecem no mercado de trabalho até essa idade.

\subsection{Perfis salariais: um olhar adicional sobre educação e gênero no Brasil}

Os diferenciais de remuneração apresentados na Tabela 1 poderiam ser oriundos de outras características observáveis, além do tipo de vínculo empregatício público ou privado. ${ }^{6}$ Tendo como base a literatura sobre o tema, seria razoável inferir que diferenças de educação e gênero possam explicar parte significativa desses diferenciais. No entanto, parece que no caso da carreira docente, a escolaridade não desempenha papel tão relevante. Conforme mostram os dados da Tabela 2, a relação entre a escolaridade média dos professores das duas redes é muito próxima de l. Ou seja, não há diferença significativa entre os dois grupos e, desta forma, não se pode inferir que as diferenças apontadas na Tabela 1 sejam devidas à escolaridade. Uma possível explicação para esse fato é que a carreira docente apresenta uma especificidade: o nível educacional é uma exigência para a docência. Desta maneira, todos aqueles que ministram aula em um determinado nível de ensino devem atender a um requisito mínimo de escolaridade, seja na rede pública ou privada. Esta exigência faz com que haja reduzida diferenciação entre os docentes das duas redes quanto ao quesito escolaridade.

5 Esse ponto é levantado por Krawczyk (2003), como parte de sua reflexão sobre o ensino médio no Brasil.

6 Os autores agradecem a um parecerista anônimo pelo comentário que motivou a análise efetuada nesta seção. 
A única exceção ao padrão de resultados são os docentes da pré-escola, pertencentes às duas coortes mais idosas. Porém, nesse caso, os resultados talvez devam ser explicados por viés de seleção, visto que provavelmente uma parcela maior dos docentes da rede privada com remuneração mais elevada deixou o mercado de trabalho antes dos seus congêneres com remuneração mais baixa. Note-se, ainda, que os docentes de pré-escola representam uma parcela diminuta do total de professores, o que faz com que a diferença verificada seja pouco expressiva.

TABELA 2 - RELAÇÃO ENTRE AS MÉDIAS DE ESCOLARIDADE DOS DOCENTES DAS REDES PÚBLICA E PRIVADA, POR COORTE E NÍVEL DE ENSINO (VALORES EM R\$/MÊS - SET./2000)

\begin{tabular}{lcccccccccc}
\hline Nível de ensino & \multicolumn{10}{c}{ Coorte (idade) } \\
\cline { 2 - 11 } & $20-24$ & $25-29$ & $30-34$ & $35-39$ & $40-44$ & $45-49$ & $50-54$ & $55-59$ & $60-64$ & $>65$ \\
\hline Pré-escola & 0,97 & 0,97 & 0,96 & 0,95 & 0,97 & 0,95 & 1,01 & 1,05 & 0,88 & 0,80 \\
Fundamental - Primário & 0,98 & 0,99 & 0,99 & 0,99 & 1,00 & 1,00 & 1,00 & 0,99 & 0,97 & 0,99 \\
Fundamental - Ginásio & 0,97 & 0,98 & 0,99 & 0,98 & 0,99 & 0,99 & 0,99 & 1,00 & 1,00 & 1,00 \\
Médio & 0,99 & 1,00 & 1,00 & 0,99 & 1,00 & 1,00 & 1,00 & 1,00 & 1,00 & 1,03 \\
Superior & 1,04 & 0,99 & 1,01 & 1,02 & 1,01 & 1,01 & 1,01 & 1,02 & 1,00 & 1,00 \\
\hline
\end{tabular}

Raciocínio análogo aplica-se à importância do gênero na explicação dos diferenciais de remuneração. As Tabelas 3 e 4 apresentam a relação entre as médias de escolaridade dos docentes, por coorte e nível de ensino, agora separados por gênero. Como pode ser notado, de forma similar ao verificado na Tabela 2 , as diferenças educacionais por gênero são muito reduzidas. Novamente, a exceção ao padrão verificado continuam sendo os professores mais idosos da pré-escola. Desta maneira, os dados das três tabelas desta seção nos permitem concluir que diferenças educacionais e de gênero não parecem ter grande relevância na explicação dos diferenciais de remuneração entre os docentes das redes pública e privada.

TABELA 3 - RELAÇÃO ENTRE AS MÉDIAS DE ESCOLARIDADE DOS DOCENTES DO SEXO MASCULINO POR COORTE E NÍVEL DE ENSINO (VALORES EM R\$/MÊS - SET./2000)

\begin{tabular}{lcccccccccc}
\hline Nível de ensino & \multicolumn{10}{c}{ Coorte (idade) } \\
\cline { 2 - 12 } & $20-24$ & $25-29$ & $30-34$ & $35-39$ & $40-44$ & $45-49$ & $50-54$ & $55-59$ & $60-64$ & $>65$ \\
\hline Pré-escola & 0,94 & 1,22 & 1,14 & 0,95 & 2,17 & 1,16 & 1,52 & 0,82 & 0,25 & - \\
Fundamental - Primário & 0,99 & 1,01 & 0,99 & 0,99 & 1,00 & 1,02 & 0,99 & 1,05 & 1,00 & 0,96 \\
Fundamental - Ginásio & 0,96 & 0,97 & 0,94 & 0,98 & 0,99 & 0,98 & 0,98 & 0,94 & 1,00 & 1,25 \\
Médio & 1,00 & 1,01 & 1,00 & 1,00 & 1,02 & 1,01 & 1,00 & 1,02 & 0,99 & 1,03 \\
Superior & 1,03 & 0,99 & 1,01 & 1,02 & 1,00 & 1,01 & 1,01 & 1,03 & 1,02 & 1,00 \\
\hline
\end{tabular}




\section{TABELA 4 - RAZÃO DA ESCOLARIDADE MÉDIA DOS DOCENTES DO SEXO FEMININO POR COORTE E NÍVEL DE ENSINO (VALORES EM R\$/MESS - SET./2000)}

\begin{tabular}{lcccccccccc}
\hline Nível de ensino & \multicolumn{10}{c}{ Coorte (idade) } \\
\cline { 2 - 11 } & $20-24$ & $25-29$ & $30-34$ & $35-39$ & $40-44$ & $45-49$ & $50-54$ & $55-59$ & $60-64$ & $>65$ \\
\hline Pré-escola & 0,97 & 0,97 & 0,96 & 0,95 & 0,96 & 0,95 & 1,00 & 1,05 & 0,92 & 0,80 \\
Fundamental - Primário & 0,99 & 0,99 & 0,99 & 0,99 & 1,00 & 0,99 & 1,00 & 0,98 & 0,96 & 0,99 \\
Fundamental - Ginásio & 0,98 & 0,98 & 0,99 & 0,98 & 0,99 & 0,99 & 0,99 & 1,00 & 0,99 & 0,97 \\
Médio & 0,99 & 0,99 & 0,99 & 0,99 & 0,99 & 1,00 & 1,00 & 0,98 & 1,00 & 1,00 \\
Superior & 1,03 & 0,99 & 1,00 & 1,02 & 1,02 & 1,00 & 1,00 & 1,01 & 0,97 & 1,02 \\
\hline
\end{tabular}

\subsection{Perfis salariais: Estado de São Paulo}

A subseção anterior mostrou o perfil dos salários médios no Brasil. Nesta subseção, desenvolve-se o mesmo exercício para o Estado de São Paulo e comparam-se seus resultados com os dados médios do País. A Tabela 5 indica que em São Paulo o professor da rede pública recebe um salário médio superior à média nacional. Ao se comparar as redes pública e privada é possível perceber que o salário relativo público/ privado é maior em São Paulo do que no resto do Brasil. No Gráfico 1, nota-se que os salários dos professores paulistas são superiores à média nacional, tanto na rede pública como na privada. No entanto, diferentemente da média nacional, os salários na rede pública paulista são mais elevados que na rede privada. ${ }^{7}$ Nas faixas etárias mais elevadas, nota-se uma elevação da variância nos perfis salariais. Possivelmente tal fato se deve ao menor número de docentes ativos após os 55 anos, visto que esses podem se aposentar de forma precoce. Uma outra possível explicação, complementar, é que uma parte desses profissionais se aposente, mas continue trabalhando (esse fato é facultado pela legislação brasileira), porém, alterando sua decisão de oferta de trabalho.

A tendência de o salário público relativo ao privado ser maior em São Paulo do que no resto do País é observada também no primário (ver Gráfico 2). Nesse caso, o salário da rede pública é mais próximo do salário da rede privada em São Paulo do que a média nacional. Analisando o perfil dos salários dos professores no ginásio (Gráfico 3), São Paulo continua pagando um salário na rede pública pelo menos

7 Aplicam-se aos professores paulistas os mesmos argumentos apresentados na seção 4.2 para os docentes de todo o Brasil quanto aos diferenciais por educação e gênero. Por questão de espaço as tabelas correspondentes não são aqui apresentadas. Na seção 7 os cálculos são feitos de forma diferenciada para homens e mulheres. 
igual ao da iniciativa privada, com exceção da faixa etária entre 40 e 44 anos, em que ocorre uma súbita elevação do salário privado.

TABELA 5 - PERFIL SALARIAL DOS PROFESSORES DO ESTADO DE SÃO PAULO POR COORTE E REDE DE ENSINO (VALORES EM R \$/ $M \hat{E} S$ - SET./2000)

\begin{tabular}{|c|c|c|c|c|c|c|c|c|c|c|}
\hline \multicolumn{11}{|c|}{ Coorte (Idade) } \\
\hline & $20-24$ & $25-29$ & $30-34$ & $35-39$ & $40-44$ & $45-49$ & $50-54$ & $55-59$ & $60-64$ & $>65$ \\
\hline \multicolumn{11}{|c|}{ Pré-escola } \\
\hline Público & 440 & 529 & 711 & 735 & 760 & 816 & 768 & 1105 & 538 & - \\
\hline Privado & 407 & 566 & 652 & 724 & 717 & 781 & 792 & 534 & 1243 & 597 \\
\hline \multicolumn{11}{|c|}{ Fundamental - Primário } \\
\hline Público & 692 & 852 & 977 & 1061 & 1093 & 1241 & 1256 & 1210 & 1353 & 1110 \\
\hline Privado & 617 & 850 & 999 & 1100 & 1176 & 1255 & 1356 & 1396 & 1304 & 1577 \\
\hline \multicolumn{11}{|c|}{ Fundamental - Ginásio } \\
\hline Público & 538 & 703 & 813 & 854 & 899 & 987 & 1043 & 1095 & 907 & 937 \\
\hline Privado & 505 & 675 & 806 & 907 & 1223 & 1031 & 1047 & 1128 & 982 & 896 \\
\hline \multicolumn{11}{|c|}{ Médio } \\
\hline Público & 538 & 703 & 813 & 854 & 899 & 987 & 1043 & 1095 & 907 & 937 \\
\hline Privado & 505 & 675 & 806 & 907 & 1223 & 1031 & 1047 & 1128 & 982 & 896 \\
\hline \multicolumn{11}{|c|}{ Superior } \\
\hline Público & 772 & 1901 & 2493 & 3018 & 3417 & 3962 & 3961 & 4932 & 4443 & 4579 \\
\hline Privado & 1056 & 1736 & 2221 & 2686 & 3351 & 3429 & 3359 & 3394 & 4196 & 4254 \\
\hline
\end{tabular}

Assim como ocorre para o plano nacional, no ensino médio de São Paulo é possível notar um maior diferencial favorável à rede privada (Gráfico 4). Entretanto, este diferencial é inferior ao nacional. Da mesma maneira que se observa para o País como um todo, o professor do curso superior da rede pública recebe um salário superior ao pago na rede privada. De forma análoga aos demais níveis de ensino, o nível salarial paulista é maior também no ensino superior (Gráfico 5). Esta vantagem salarial do professor paulista reduz-se no nível superior. 
GRÁFICO 1 - PERFIL SALARIAL DOS PROFESSORES DA PRÉ-ESCOLA BRASIL E SÃO PAULO (VALORES EM R\$/MÊS DE 2000)

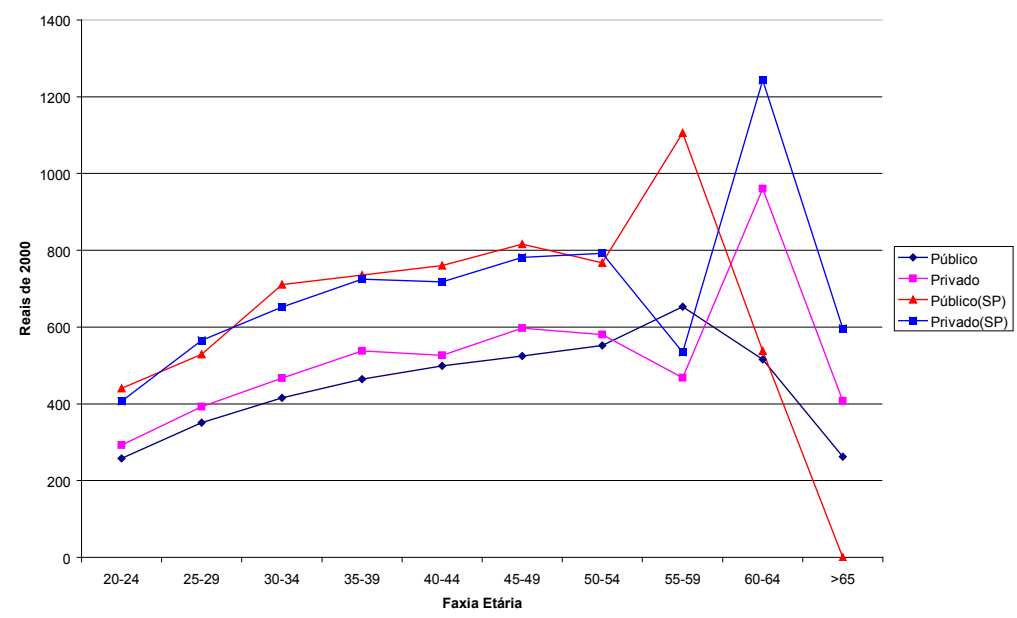

GRÁFICO 2 - PERFIL SALARIAL DOS PROFESSORES DO ENSINO FUNDAMENTAL (PRIMÁRIO) - BRASIL E SÃO PAULO (VALORES EM $R \$ / M E \hat{S} D E 2000)$

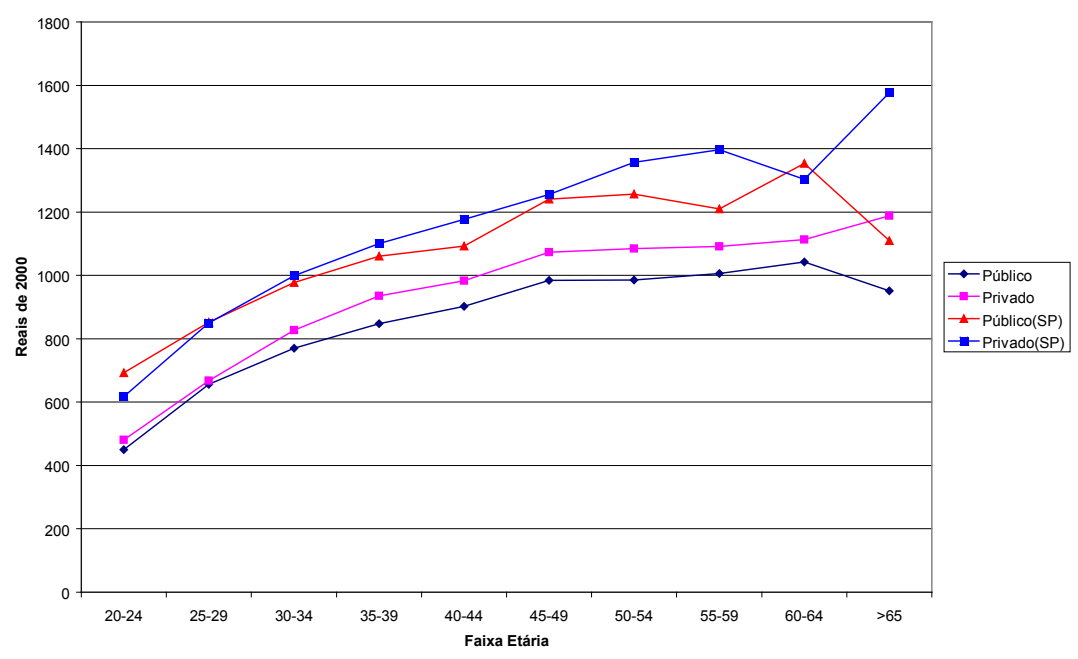


GRÁFICO 3 - PERFIL SALARIAL DOS PROFESSORES DO ENSINO FUNDAMENTAL (GINÁSIO) - BRASIL E SÃO PAULO (VALORES EM R\$/ $M \hat{E S} D E$ 2000)

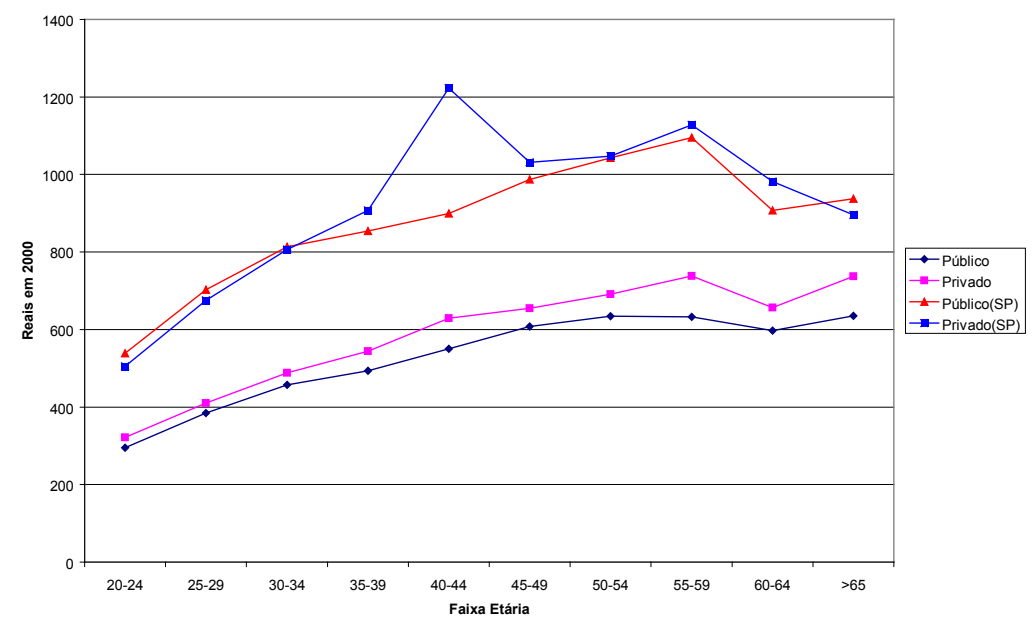

GRÁFICO 4 - PERFIL SALARIAL DOS PROFESSORES DO ENSINO MÉDIO - BRASIL E SÃO PAULO (VALORES EM R\$/MÊS DE 2000)

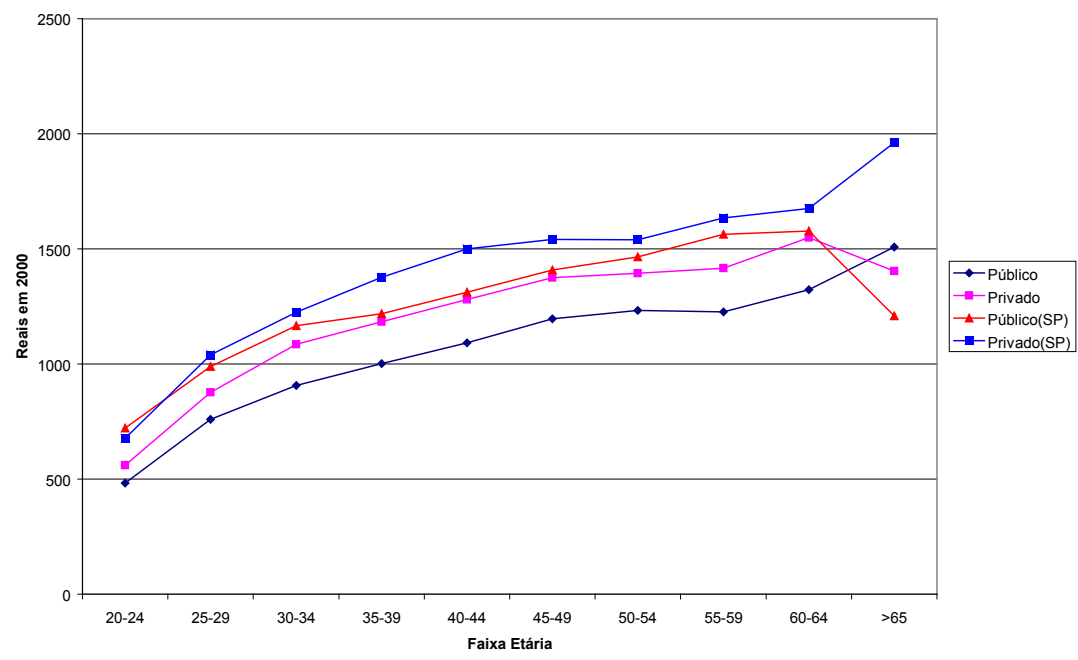




\section{GRÁFICO 5 - PERFIL SALARIAL DOS PROFESSORES DO ENSINO SUPE- RIOR - BRASIL E SÃO PAULO (VALORES EM R\$/MÊS DE 2000)}

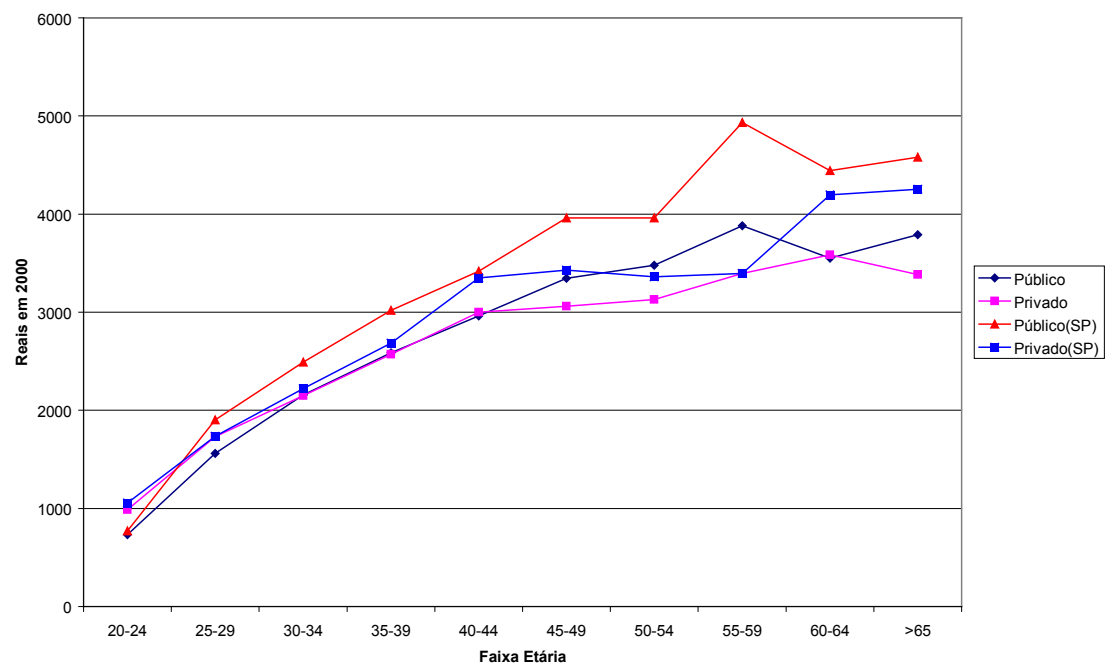

\section{DIFERENCIAIS SALARIAIS: BRASIL}

Nesta seção são calculados os diferenciais de salários entre os professores das redes de ensino pública e privada. A Tabela 6 apresenta os resultados. De forma geral é possível afirmar que os docentes da rede pública tiveram uma redução em sua remuneração relativa aos docentes da rede privada. Os dados mostram, por exemplo, que em 1980 um professor primário da rede pública ganhava em média 31\% a mais que seu similar da rede privada. Em 1991, este diferencial havia caído para 7\% e em 2000, a relação era de apenas $94 \%$. Esse padrão repete-se para os outros níveis de ensino.

\section{TABELA 6 - DIFERENCIAIS SALARIAIS PÚBLICO/PRIVADO POR REDE DE ENSINO - BRASIL}

\begin{tabular}{|c|c|c|c|c|c|c|}
\hline \multirow[t]{3}{*}{ Ano } & \multicolumn{6}{|c|}{ Nível de ensino } \\
\hline & \multirow[t]{2}{*}{ Pré-escola } & \multicolumn{2}{|c|}{ Fundamental } & \multirow[t]{2}{*}{ Médio } & \multirow[t]{2}{*}{ Profissional } & \multirow[t]{2}{*}{ Superio } \\
\hline & & Primário & Ginásio & & & \\
\hline 1980 & 1,11 & 1,31 & 1,22 & 1,13 & 1,50 & 1,20 \\
\hline 1991 & 1,22 & 1,07 & 1,00 & 0,96 & 1,14 & 1,23 \\
\hline 2000 & 0,95 & 0,94 & 0,94 & 0,89 & 1,14 & 1,07 \\
\hline
\end{tabular}


Com a crise da economia brasileira na década de 80 , de certa forma seria esperada uma redução no diferencial público-privado, representado por uma queda nos valores da Tabela 6. Mas o período analisado também foi marcado por baixas taxas de crescimento econômico, o que pode ter afetado os salários do setor privado. Entre 1991 e 2000, o diferencial cai para todos os níveis de ensino. Este resultado é provavelmente fruto do processo de estabilização por que passou a economia brasileira, que demandou esforços para aumentar o superávit primário, o que pode ter implicado menores taxas de crescimento nos salários reais dos docentes da rede pública em relação aos docentes da rede privada. O diferencial passa a ser de no mínimo 0,11 no ensino médio. Ou seja, um professor do nível médio público recebe $89 \%$ do salário pago no ensino privado. É possível que esse diferencial, relativamente baixo, possa ser compensado com benefícios existentes apenas no setor público. Essa hipótese será investigada na seção 7 .

De forma análoga ao apresentado na seção anterior, faz-se aqui uma análise dos diferenciais salariais entre as redes pública e privada para os diversos níveis de ensino, desta vez para todos os Estados brasileiros.

\subsection{Pré-escola}

Os dados da Tabela 7 mostram que o Distrito Federal e o Amapá estão entre os cinco maiores diferenciais pró-servidor público nos três anos analisados. Há grande queda no diferencial do Rio de Janeiro. Neste Estado, que se encontrava em 1980 e 1991 no grupo com maior diferencial, houve expressiva alteração em 2000, e o prêmio do setor público passou a ser apenas $2 \%$ favorável ao setor público. Por outro lado, os Estados do Acre, Paraíba e Maranhão apresentaram uma grande elevação neste diferencial. Em 1980, a diferença era favorável à iniciativa privada e em 2000 nota-se uma mudança, tornando-se favorável ao setor público.

Entre os Estados com baixo diferencial, o Ceará e a Bahia mantêm a relação vista entre 1981 e 1990. É importante ressaltar que na maioria dos Estados com diferenciais favoráveis ao setor privado, houve uma melhora entre 1991 e 2000. Ou seja, de forma geral, os diferenciais salariais reduziram-se. Já a pré-escola apresenta em 1980 um diferencial positivo para 10 Estados. Em 1991, este número amplia-se para 14 e volta a cair em 2000 para 13 Estados. 


\subsection{Ensino fundamental - Primário}

Na Tabela 8 são apresentados os resultados relativos ao ensino primário. O Rio de Janeiro permanece entre os Estados com maior diferencial para o servidor público nos três anos analisados. Entretanto, este diferencial foi reduzido drasticamente, de 68\% em 1980 para 10\% em 2000. Estados como Rondônia e Tocantins apresentam uma enorme melhora, saindo de um salário pago na rede pública até $9 \%$ inferior ao pago na rede privada para salários que pagam até $39 \%$ a mais na rede pública em relação à privada.

Os Estados com pior diferencial em 1980 pagavam no máximo $11 \%$ a menos no setor público. Este número amplia-se para até $29 \%$ em 1991, sendo provavelmente fruto da crise fiscal que o País atravessou na década de 80. Entretanto, de 1991 até 2000 esta diferença reduz-se para um máximo de $22 \%$. Mais uma vez o Ceará surge em 2000 como um dos Estados com maior diferencial em favor da rede privada, acompanhado de Pernambuco, Sergipe e Amapá. Em 1980, há 17 Estados que pagam salários maiores na rede pública. Em 1991, este número cai para 13 e reduz-se para $10 \mathrm{em} 2000$.

\subsection{Ensino fundamental - Ginásio}

No ginásio (Tabela 8) observa-se um grande diferencial em favor dos professores da rede pública no RJ e em DF em todo o período analisado. O Estado com diferencial mais desfavorável ao docente do ginásio é mais uma vez o Ceará, no qual o valor calculado é de apenas 0,84. Todos os outros Estados pagam, na pior das hipóteses, um salário 9\% inferior ao da iniciativa privada. Isto é, o salário pago no ginásio é bastante próximo entre a iniciativa privada e o setor público. Em 1980, 16 Estados pagavam na rede pública um salário superior ao da rede privada. Já em 1991, o número de Estados cai para 10 e volta a se elevar para 12 em 2000.

\subsection{Ensino médio}

É no ensino médio que se observa em 2000 a maior diferença entre os salários pagos nos setores privado e público. Em quase metade dos Estados paga-se um salário mais de $10 \%$ inferior à iniciativa privada. Sergipe é o Estado com o maior diferencial de salário em favor da rede pública em 1980, seguido pela Paraíba, com diferenciais em favor do servidor público da ordem de $61 \%$ e 58\%, respectivamente. Em 2000, em Sergipe, os professores da rede pública recebiam $35 \%$ menos que seus pares do setor privado. Já na Paraíba mantém-se este diferencial positivo em 2000, oferecendo na 
rede pública um salário 21\% superior ao pago na rede privada. Entretanto, ocorre uma perda significativa em 1991, com o diferencial ficando desfavorável para o servidor público em $29 \%$. Duas possíveis explicações para esta variabilidade são a data esparsa das negociações salariais e a elevada inflação do período.

No Rio de Janeiro, os professores da rede privada que em 1980 recebiam um salário $24 \%$ superior ao pago na rede pública perdem espaço para os professores da rede privada nas duas décadas que seguiram. Em 1991 e 2000, o diferencial deixa de existir e os salários são praticamente os mesmos. Em 1980, 20 Estados pagavam um diferencial positivo para o setor privado. Em 1991, este número cai para 12 Estados. Em 2000, somente sete Estados apresentam um diferencial favorável ao setor privado. É no nível médio que são verificadas as maiores diferenças entre o público e o privado.

\subsection{Ensino superior}

Os resultados referentes ao nível superior seguem o padrão verificado para os outros níveis de ensino. Há um diferencial favorável ao professor do ensino público, com pequena queda na década de 90. A Tabela 11 mostra que em 1980 apenas o Acre tinha um diferencial favorável ao setor privado. Esta situação muda pouco até 1991, quando apenas o Estado do Mato Grosso do Sul apresenta um salário público inferior em $24 \%$ ao privado. No ano 2000, ocorrem algumas mudanças e sete Estados pagam mais no setor privado. Em apenas três Estados esta diferença supera os 10\% para o ano 2000: Goiás, Amazonas e Sergipe.

Um ponto em comum entre a grande maioria dos níveis de ensino é a redução do grau de dispersão que ocorre entre 1980 e 2000. Pelas tabelas acima, pode-se perceber que os diferenciais extremos caem entre 1980 e 2000. Ou seja, os diferenciais aproximam-se de 1. Entretanto, o mesmo não ocorre na parte inferior dos diferenciais. Os diferenciais mais desfavoráveis não são reduzidos em direção favorável aos empregados da rede pública. No primário, médio e superior este fato não é observado. A redução do grau de dispersão entre 1980 e 2000 pode ser observada na Tabela 12. Entretanto, esta variância não cai de forma sistemática em todos os anos. O aumento da variância em 1991 pode ser causado pelos efeitos inflacionários. Em períodos de elevada inflação, a data da coleta dos dados pode influenciar este diferencial, uma vez que nas datas de renegociação salarial os salários reais estão bastante corroídos pela inflação. Desta forma, caso as datas sejam diferentes entre os Estados e entre o setor público e o privado, pode se verificar elevação da variância. 


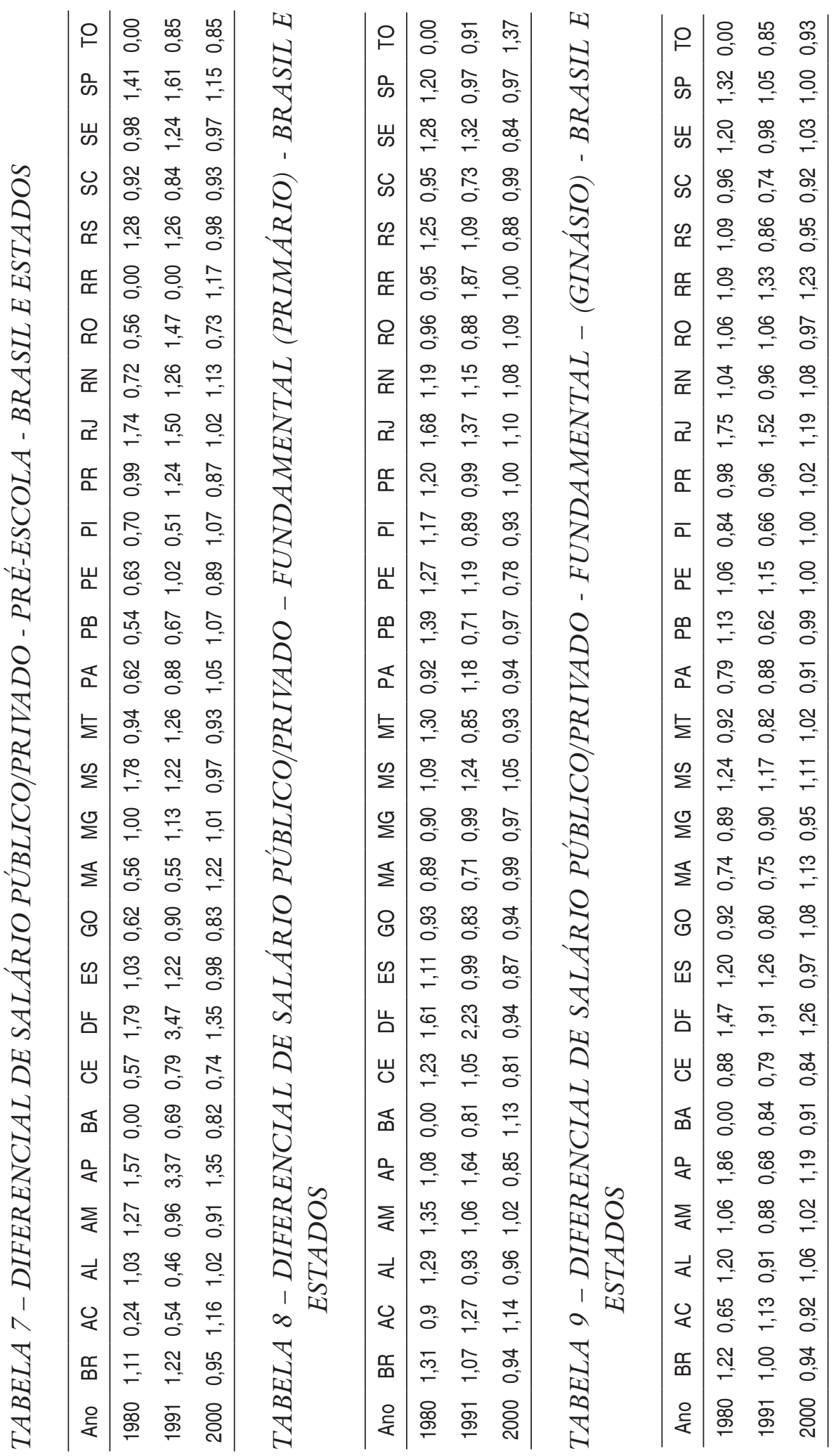




\begin{tabular}{|c|c|c|c|c|c|c|c|}
\hline 은 & 8 导 & $\begin{array}{l}\frac{L}{2} \\
0 \\
0\end{array}$ & & $\stackrel{\circ}{\circ}$ & 8 & $œ$ & $\stackrel{\mathbb{N}}{=}$ \\
\hline के & \begin{tabular}{ll}
$\infty$ \\
0 \\
\hdashline
\end{tabular} & ஜூ & & क & $\stackrel{\Sigma}{\sim}$ & $\stackrel{d}{\stackrel{I}{\leftarrow}}$ & $\stackrel{0}{=}$ \\
\hline 贸 & $\bar{\sigma}$ & $\mathscr{6}$ & & 岗 & s. & छे & 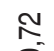 \\
\hline 0 & $\mathscr{N} \approx$ & ৪ & & O & $\therefore$ & \llcorner & $\stackrel{\infty}{\sim}$ \\
\hline$\omega$ & 00 & 0 & 0 & क & $=$ & $=$ & $=$ \\
\hline 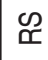 & $\cong 0$ & $\begin{array}{l}\text { s. } \\
\text { o } \\
0\end{array}$ & 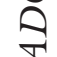 & $\mathscr{\Upsilon}$ & $\stackrel{\infty}{\infty}$ & $\stackrel{m}{\sigma}$ & 8 \\
\hline 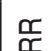 & హ్ & g్ & $\hat{n}$ & $\stackrel{\mathfrak{r}}{\widetilde{r}}$ & 8 & 8 & 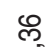 \\
\hline & $\odot \propto$ & $\infty$ & 1 & 0 & 8 & $\approx$ & $\overline{8}$ \\
\hline$\ddot{x}$ & 0 & $0^{\infty}$ & 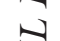 & $\approx$ & 0 & $=$ & $\stackrel{0}{=}$ \\
\hline zo & $\stackrel{8}{\circ}$ & ช్ & $\sqrt{\pi}$ & $\underset{x}{z}$ & $\hat{m}$ & స్ & $\bar{m}$ \\
\hline & 0 & $\sim$ & $\approx$ & & 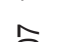 & $\approx$ & \\
\hline$q^{2}$ & $\cong$ & $\stackrel{\circ}{=}$ & $\infty$ & $\Upsilon^{2}$ & $\stackrel{\circ}{\circ}$ & $\stackrel{N}{-}$ & $=$ \\
\hline$\stackrel{\dddot{\alpha}}{\alpha}$ & 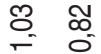 & $\begin{array}{l}8 \\
\circ \\
0\end{array}$ & $\widetilde{\Omega}$ & 路 & 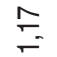 & $\stackrel{0}{=}$ & ֻூ \\
\hline $\bar{\alpha}$ & 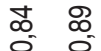 & 志 & $\approx$ & $\bar{\alpha}$ & $\stackrel{\infty}{m}$ & $\overline{0}$ & $q_{-}$ \\
\hline ш & $\therefore \hat{o}$ & $\bar{\infty}$ & 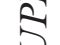 & 山 & ล & g & I \\
\hline & - & 0 & $\tilde{\omega}$ & & & - & \\
\hline$\stackrel{m}{\alpha}$ & 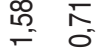 & $\stackrel{\Sigma}{\stackrel{N}{-}}$ & & $\stackrel{\emptyset}{\alpha}$ & ले & $\stackrel{m}{=}$ & $\stackrel{\stackrel{Q}{N}}{=}$ \\
\hline$\varangle$ & 으 & পু & 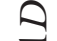 & $\varangle$ & $\stackrel{0}{\circ}$ & g & ช \\
\hline & - & 0 & $\Delta$ & & - & - & $0^{\circ}$ \\
\hline$\stackrel{E}{\Sigma}$ & 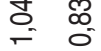 & ח్ & $\approx$ & $\stackrel{5}{\Sigma}$ & $\underset{\widetilde{G}}{-}$ & $\stackrel{10}{=}$ & $\stackrel{\mathscr{m}}{=}$ \\
\hline$\sum_{\sum}^{\infty}$ & $\mp$ s & $\infty$ & $\widehat{\widehat{\sigma}}$ & $\sum^{\infty}$ & $\mathscr{p}$ & 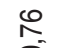 & б. \\
\hline (v) & ஜ & ஓ & & ర్ & F & 요 & 8 \\
\hline$\Sigma$ & $=$ & 0 & 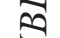 & $z$ & $=$ & $=$ & $=$ \\
\hline$\sum$ & $\stackrel{g}{g}$ & $\stackrel{8}{\circ}$ & is & $\sum$ & $\underset{f}{g}$ & 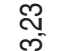 & ్ㅗㄴ \\
\hline 엄 & N & ֻ & $\supseteqq$ & ০ & ల్ & ㅇ. & 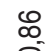 \\
\hline$\infty$ & ભ & $\mathscr{8}$ & 7 & $\infty$ & $\widehat{s}$ & $\sqrt{0}$ & Z \\
\hline Ш & $=$ & $0^{\circ}$ & $\exists$ & ய & $=$ & $\stackrel{2}{=}$ & 0 \\
\hline 㟔 & 으 곡 & 8 & $山$ & 㟔 & 요 & $\begin{array}{l}\infty \\
1\end{array}$ & $\stackrel{2}{2}$ \\
\hline & $\sim$ & $m$ & 닝 & & $\nabla$ & 0 & 6 \\
\hline$\overline{0}$ & $=$ & 0 & - & 0 & $=$ & $\stackrel{3}{-}$ & $\cong$ \\
\hline ळ̋ & 8 & $\frac{9}{2}$ & $\nabla$ & 品 & 8 & $\bar{N}$ & $\cong$ \\
\hline & + & ما & & & 0 & & \\
\hline 逃 & ${ }_{0}^{\infty}$ & o. & 团 & 岩 & O. & 용 & $\stackrel{\circ}{=}$ \\
\hline$\sum_{<}$ & $\cong$ & $\stackrel{\llcorner}{\infty}$ & $\mathbb{1}$ & $\sum$ & 尺 & 寺 & $\infty$ \\
\hline & & $\checkmark$ & & & & & \\
\hline 安 & $0^{\infty}$ & $=$ & & $\vec{\varangle}$ & $\stackrel{m}{=}$ & $\stackrel{=}{=}$ & 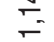 \\
\hline O & חొ & ల్ల & $=$ & 0 & $\infty$ & 8 & $\stackrel{\nabla}{\sim}$ \\
\hline & $m$ & & & & & & \\
\hline 菂 & $=0$ & $\stackrel{\infty}{0}^{\infty}$ & & 鬲 & $\stackrel{\cong}{=}$ & $\stackrel{\text { N }}{-}$ & 음 \\
\hline$\frac{0}{4}$ & পু চ্ণ & ৪ి & 7 & 운 & $\stackrel{\circ}{\circ}$ & হু & 8 \\
\hline
\end{tabular}




\section{TABELA 12 - VARIÂNCIA DOS DIFERENCIAIS DE SALÁRIO PÚBLICO- PRIVADO}

\begin{tabular}{lccc}
\hline & \multicolumn{3}{c}{ Ano } \\
\cline { 2 - 4 } Nível de ensino & 1980 & 1991 & 2000 \\
\hline Pré-escola & 0,267 & 0,566 & 0,026 \\
Fundamental - Primário & 0,139 & 0,125 & 0,015 \\
Fundamental - Ginásio & 0,160 & 0,079 & 0,011 \\
Médio & 0,140 & 0,164 & 0,034 \\
Profissional & 0,389 & 0,452 & 0,107 \\
Superior & 0,297 & 0,503 & 0,033 \\
\hline
\end{tabular}

\section{O VALOR PRESENTE DO CONTRATO DE TRABALHO (VPCT)}

Nas seções anteriores foram comparados os salários dos docentes das redes pública e privada. No entanto, parece ser necessário incorporar à análise as particularidades referentes à oferta de trabalho e à remuneração no Brasil. A mais importante delas é a influência que a previdência social tem sobre os rendimentos recebidos ao longo da vida dos trabalhadores. Apesar das reformas recentes, trabalhadores do setor privado, vinculados ao INSS, ainda têm obrigações e direitos distintos dos funcionários públicos. Dado este fato, nesta seção comparamos os empregos docentes nas redes pública e privada levando em consideração não apenas o salário direto pago, como também os benefícios previdenciários associados a cada posição na ocupação.

\subsection{Metodologia de cálculo do Valor Presente do Contrato de Trabalho}

Nesta seção é apresentado o Valor Presente do Contrato de Trabalho (VPCT). O VPCT é inspirado no conceito da Social Security Wealth apresentado no clássico de Feldstein (1974) e na metodologia apresentada em Afonso e Fernandes (2005). É uma medida da renda total recebida ao longo da vida de um trabalhador. No cálculo do VPCT são englobados não somente os salários recebidos durante a vida ativa, como também a redução na renda bruta, referente à contribuição previdenciária. Por fim, são somados os benefícios previdenciários recebidos quando da aposentadoria do indivíduo. Para cada nível e rede de ensino é calculado um valor de $V P C T_{i k}$, dado pela expressão a seguir: 


$$
V P C T_{i k}=\sum_{j=o}^{A-1} \frac{w_{k j}-\tau_{j}}{(1+r)^{j}}+\sum_{j=A}^{T} \frac{b_{k j}-\gamma_{j}}{(1+r)^{j}}
$$

O subscrito $i$ refere-se à rede de ensino (pública ou privada). O subscrito $k$ indica os 6 níveis de ensino. O subscrito $j$ corresponde ao número de anos em questão. $\mathrm{O}$ trabalhador se aposenta em $A$ e vive até o período $T$. As letras $\tau$ e $\gamma$ representam, respectivamente, a contribuição paga para a previdência durante o período laboral e durante a aposentadoria (se houver contribuição dos inativos). A taxa de desconto empregada é $r$. O parâmetro $A$ representa o número de anos de trabalho necessários para a aposentadoria. $\mathrm{O}$ valor de $T$ corresponde à expectativa de vida menos a idade de entrada no mercado de trabalho.

\subsection{Divisão dos grupos com características comuns}

O primeiro passo para calcular o VPCT é definir o conjunto de parâmetros necessários para a formação de grupos com características comuns frente à previdência social. A cada grupo é aplicado um conjunto de regras previdenciárias particulares. Para o cálculo das contribuições, os seguintes parâmetros devem ser observados: renda do trabalhador, alíquota de contribuição do trabalhador, alíquota de contribuição do empregador (quando esta existir) e teto de contribuição (quando este existir) para empregadores e trabalhadores. Para o cálculo dos benefícios, os parâmetros são os seguintes: idade de aposentadoria, regra de cálculo do valor da aposentadoria, forma de reajuste do valor real da aposentadoria, alíquota de contribuição do trabalhador inativo (se esta existir).

Uma vez definidos os parâmetros, o passo seguinte consiste na divisão dos professores em categorias, de forma consistente com os dados disponíveis e com os resultados apresentados nas seções iniciais. A primeira separação é feita entre os docentes dos setores privado e público. Os docentes são também separados de acordo com o nível de ensino em que ministram suas aulas, em quatro categorias: pré-escola, fundamental (desagregado ainda em primário e ginasial) médio e superior. Para cada categoria é necessário, ainda, separar os professores por gênero, visto que na carreira docente há diferenças de tratamento por parte da previdência para homens e mulheres. Os cálculos são feitos para cada um desses subgrupos. 


\subsection{Cálculo das contribuiçôes}

Os procedimentos de cálculo das contribuições e dos benefícios seguem a forma padrão encontrada na literatura. Com base nos dados em cross-section do Censo de 2000, foi estimado um perfil salarial (e de contribuições) intertemporal por coorte para cada um dos grupos. Em outras palavras, empregam-se dados das coortes mais antigas para prever a evolução salarial das coortes mais novas. Devido às limitações que o número reduzido de observações poderia trazer, cada coorte é composta por indivíduos nascidos em um determinado quinquênio, para o qual se computa um salário médio. Por exemplo, a primeira coorte abarca as pessoas de 20 a 24 anos. Para os professores da pré-escola do setor público, pertencentes a esta coorte, a remuneração média é de R 258 mensais (ver Tabela 1). Para a coorte seguinte (dos 25 aos 29 anos) desta categoria, a remuneração eleva-se para R\$350. Esses dados são computados para todas as coortes e grupos.

Uma vez conhecidos os dados de remuneração dos professores, a cada coorte e cada grupo aplicam-se as regras de contribuição previdenciária. Para todos os grupos foram empregadas as regras vigentes em setembro de 2000. Ou seja, implicitamente supõe-se uma situação de estado estacionário. É como se um trabalhador estivesse começando sua vida ativa em 2000 e o conjunto de regras em vigor nesse ano fosse como um parâmetro suposto estável a partir do qual as escolhas ocupacionais são feitas. Para os professores do setor privado, a contribuição ao INSS é calculada pela soma da contribuição dos trabalhadores e dos empregadores. A alíquota de contribuição do empregador é de $20 \%$, sem limite superior, conforme determina o Decreto-Lei 2318, de 1986. Para o trabalhador, a alíquota de contribuição varia de acordo com a faixa de renda $\Upsilon$, conforme apresentado na Tabela 13.

\section{TABELA 13 - ALÍQUOTA DE CONTRIBUIÇÃO PREVIDENCIÁRIA DOS TRABALHADORES DO SETOR PRIVADO (SET./2000)}

\begin{tabular}{lc}
\hline Renda $Y(R \$)$ & Alíquota $(\%)$ \\
\hline$Y \leq 398,48$ & 7,72 \\
$398,49 \leq Y \leq 453,00$ & 8,73 \\
$453,01 \leq Y \leq 664,13$ & 9,00 \\
$664,14 \leq Y \leq 1328,25$ & 11,00 \\
\hline
\end{tabular}

Para os professores do setor público federal há apenas uma alíquota de $11 \%$, incidindo sobre os empregados. Para os professores da rede pública do Estado de São 
Paulo a alíquota é de 6\%, também incidindo sobre os empregados. Em ambos os casos, inexiste contribuição por parte do empregador, o governo. É possível, por meio das regras então em vigência, estimar a contribuição mensal de cada professor. Multiplicando os valores por 13 (visto que os assalariados do setor privado têm direito ao $13^{\circ}$ salário) chega-se à contribuição anual.

Adicionalmente, são feitas duas hipóteses. A primeira refere-se à data de início da docência. Considerou-se que os professores da pré-escola, dos níveis médio e fundamental começam a dar aulas aos 20 anos. Para os docentes do nível superior, dada a maior exigência educacional, supôs-se que a entrada no mercado de trabalho ocorre aos 25 anos. Implicitamente, os cálculos efetuados pressupõem uma condição de estabilidade na ocupação: o indivíduo opta pela carreira docente na rede pública ou privada no início de sua vida profissional e assim continua, até se aposentar. Em todo o trabalho adotou-se a hipótese de que as regras previdenciárias então vigentes continuarão a valer. Com essa hipótese é possível abstrair-se o impacto de regras de transição adotadas quando de mudanças previdenciárias.

\subsection{Cálculo dos beneficios}

Para o cálculo dos benefícios supõe-se que os professores seguem estritamente as regras então vigentes. Isso significa que, assim que forem cumpridos os requisitos de tempo de contribuição e idade necessários, os docentes deixam o mercado de trabalho e passam a receber os proventos da aposentadoria.

No setor privado, os professores de todos os níveis de ensino (com exceção do superior) podem se aposentar após 30 anos de serviço (homens) e 25 anos (mulheres). Para o ensino superior, essas idades mínimas são elevadas em 5 anos para ambos os sexos. O valor do benefício é calculado tendo como base a média aritmética dos 80\% melhores salários de contribuição. Sobre o valor calculado incide ainda o Fator Previdenciário, que foi criado no final de 1999. O valor do benefício é limitado ao teto do INSS. Ao longo do tempo, com base na regra de manutenção do poder de compra dos benefícios adotada pelo governo, supõe-se que o valor real da aposentadoria não sofrerá modificações.

Para os docentes do setor público há diferenças importantes. Estes profissionais têm direito a dois privilégios inacessíveis a seus pares da iniciativa privada. O primeiro é a aposentadoria integral, de valor equivalente ao último salário que tinham quando estavam na ativa. O segundo privilégio é a paridade, que permite aos aposentados do setor público ter seus benefícios aumentados em termos reais às mesmas taxas verificadas para os funcionários ativos. Por esse motivo, utilizando o perfil salarial de 
cada categoria dos professores do setor público foram estimadas taxas de crescimento anuais dos salários. Essas taxas foram aplicadas aos benefícios, de forma a mimetizar a política de paridade adotada. Para os docentes aposentados do setor público do Estado de São Paulo há a incidência de uma alíquota de 6\% sobre as aposentadorias. Outro parâmetro relevante para esse tipo de cálculo é o período de recebimento da aposentadoria. Tendo como base a expectativa de vida média do brasileiro, supôs-se que os aposentados vivem até os 75 anos de idade.

\subsection{Resultados}

Com base no cálculo de salários e benefícios é possível expressar os resultados por meio do valor presente da renda ao longo do ciclo de vida dos indivíduos. Incluem-se aqui todos os rendimentos líquidos, tanto salariais quanto previdenciários, obtidos pelos docentes ao longo de sua vida. Para isso são calculados os valores presentes dos fluxos de renda obtidos por cada pessoa. Nos cálculos foram empregadas taxas de desconto de $3 \%$ a $7 \%$ ao ano. Essa escolha deve-se ao fato de que nos últimos 40 anos a taxa real de juros no Brasil foi da ordem de $5 \%$.

São comparados os VPCTs do emprego de professor nas rede pública e privada para os diferentes níveis de ensino. De forma geral, observa-se que o diferencial em favor do professor da rede pública é maior em São Paulo do que no resto do Brasil. O nível médio é onde se verifica o diferencial menos favorável aos professores da rede pública. Podemos observar, também, que a pré-escola é onde se oferece o VPCT mais reduzido. Um fato curioso é o menor VPCT do professor do ginásio em relação ao do professor do primário. Os professores que atuam no ensino superior possuem os empregos com maior VPCT, apesar de o diferencial não ser tão elevado. ${ }^{8}$

\subsubsection{Valor Presente do Contrato de Trabalho das professoras}

De forma geral, as mulheres possuem uma grande vantagem ao optar pelo emprego na rede pública de ensino. Isto pode ser observado através do diferencial positivo que o emprego na rede pública lhes oferece. Este fato decorre da regra que permite à mulher trabalhar cinco anos a menos do que o homem para se aposentar. Desta forma, estas começam a receber seus benefícios cinco anos antes, em um período em que aqueles ainda contribuem.

8 Todos os resultados apresentados nesta seção poderiam ser desmembrados por gênero e educação dos docentes. Por questão de espaço, estes cálculos não são apresentados. Adicionalmente, pode-se afirmar, com base nos dados da seção 4.2, que educação e gênero não representam fatores tão importantes para a explicação dos diferenciais de remuneração. 
A Tabela 14 mostra os diferenciais de VPCT para as professoras do Brasil. É no ensino médio que a rede pública oferece a menor renda em comparação com a rede privada. Com uma taxa de desconto de $5 \%$ ao ano, o VPCT de uma professora da rede pública oferece diferenciais que variam de $13 \%$ (superior) a $25 \%$ (primário), com um diferencial absoluto superior a $\mathrm{R} \$ 46.000,00$ no superior. Com taxas de desconto mais elevadas, o diferencial a favor da rede pública é reduzido. Isto ocorre porque uma taxa de desconto maior desconta mais fortemente o valor presente da aposentadoria, cujos fluxos estão mais distantes no tempo. A aposentadoria é recebida pelo indivíduo com uma idade mais avançada, sendo portanto mais influenciada pela taxa de desconto. Com uma taxa de desconto de 7\%, há um diferencial favorável ao ensino público nos níveis médio e superior, de apenas $4 \%$ e $7 \%$, respectivamente.

TABELA 14 - DIFERENCIAIS DE VPCT - PROFESSORAS DAS REDES PÚBLICA E PRIVADA (BRASIL) - VALORES EM R\$ (SET./2000)

\begin{tabular}{|c|c|c|c|c|c|}
\hline & \multicolumn{5}{|c|}{ Nível de ensino } \\
\hline & \multirow[t]{2}{*}{ Pré-Escola } & \multicolumn{2}{|c|}{ Fundamental } & \multirow[t]{2}{*}{ Médio } & \multirow[t]{2}{*}{ Superior } \\
\hline & & Primário & Ginásio & & \\
\hline & \multicolumn{5}{|c|}{ Taxa de Desconto: $3 \%$} \\
\hline VPCT Público & $159.785,43$ & $289.558,56$ & $179.669,67$ & $320.304,66$ & $678.346,90$ \\
\hline VPCT Privado & $120.854,01$ & $205.338,69$ & $128.020,58$ & $242.854,85$ & $541.041,63$ \\
\hline Diferencial (R\$) & $38.931,42$ & $84.219,86$ & $51.649,09$ & $77.449,81$ & $137.305,27$ \\
\hline \multirow[t]{2}{*}{ Diferencial (\%) } & $32 \%$ & $41 \%$ & $40 \%$ & $32 \%$ & $25 \%$ \\
\hline & \multicolumn{5}{|c|}{ Taxa de Desconto: $5 \%$} \\
\hline VPCT Público & $102.956,01$ & $186.033,03$ & $114.980,62$ & $203.750,56$ & $408.254,89$ \\
\hline VPCT Privado & $87.758,47$ & $148.407,21$ & $92.810,83$ & $174.997,82$ & $361.614,15$ \\
\hline Diferencial (R\$) & $15.197,54$ & $37.625,82$ & $22.169,79$ & $28.752,73$ & $46.640,73$ \\
\hline \multirow[t]{2}{*}{ Diferencial (\%) } & $17 \%$ & $25 \%$ & $24 \%$ & $16 \%$ & $13 \%$ \\
\hline & \multicolumn{5}{|c|}{ Taxa de Desconto: 7\% } \\
\hline VPCT Público & $72.397,42$ & $130.502,10$ & $80.464,68$ & $141.565,49$ & $265.212,81$ \\
\hline VPCT Privado & $67.386,26$ & $113.473,87$ & $71.198,14$ & $133.363,31$ & $253.344,59$ \\
\hline Diferencial $(\mathrm{R} \$)$ & $5.011,15$ & $17.028,23$ & $9.266,54$ & $8.202,18$ & $11.868,22$ \\
\hline Diferencial (\%) & $7 \%$ & $15 \%$ & $13 \%$ & $6 \%$ & $5 \%$ \\
\hline
\end{tabular}

A Tabela 15 apresenta os diferenciais para o Estado de São Paulo. Assim como na Tabela 14, os diferenciais são favoráveis às professoras da rede pública. Com uma 
taxa de desconto de 5\%, estes variam de 13\% (superior) a 36\% (pré-escola). Com uma taxa de desconto de 7\%, as professoras do nível superior do setor público têm um VPCT 2\% maior que no setor privado.

A remuneração dada pelo VPCT é sempre superior em São Paulo em comparação ao Brasil, assim como o diferencial entre o contrato público e o privado. A única exceção ocorre no ensino superior público, em que o diferencial é ligeiramente inferior ao do restante do Brasil, com uma taxa de desconto de 7\%. Talvez a razão seja o fato de o mercado de ensino superior privado ser mais desenvolvido em São Paulo do que no resto do País.

TABELA 15 - DIFERENCIAIS DE VPCT - PROFESSORAS DAS REDES PÚBLICA E PRIVADA (SÃO PAULO) - VALORES EM R\$ (SET./2000)

\begin{tabular}{|c|c|c|c|c|c|}
\hline & \multicolumn{5}{|c|}{ Nível de ensino } \\
\hline & \multirow[t]{2}{*}{ Pré-Escola } & \multicolumn{2}{|c|}{ Fundamental } & \multirow[t]{2}{*}{ Médio } & \multirow[t]{2}{*}{ Superior } \\
\hline & & Primário & Ginásio & & \\
\hline & \multicolumn{5}{|c|}{ Taxa de Desconto: $3 \%$} \\
\hline VPCT Público & $252.287,45$ & $363.825,80$ & $297.004,67$ & $399.618,74$ & $752.291,06$ \\
\hline VPCT Privado & $165.901,29$ & $250.710,26$ & $214.420,47$ & $290.265,66$ & $589.789,96$ \\
\hline Diferencial (R\$) & $86.386,15$ & $113.115,54$ & $82.584,20$ & $109.353,08$ & $162.501,10$ \\
\hline \multirow[t]{2}{*}{ Diferencial (\%) } & $52 \%$ & $45 \%$ & $39 \%$ & $38 \%$ & $28 \%$ \\
\hline & \multicolumn{5}{|c|}{ Taxa de Desconto: $5 \%$} \\
\hline VPCT Público & $163.793,54$ & $236.810,08$ & $193.012,74$ & $257.938,51$ & $444.117,89$ \\
\hline VPCT Privado & $120.715,09$ & $181.774,98$ & $154.093,75$ & $209.830,41$ & $394.734,93$ \\
\hline Diferencial (R\$) & $43.078,44$ & $55.035,10$ & $38.918,99$ & $48.108,10$ & $49.382,96$ \\
\hline \multirow[t]{2}{*}{ Diferencial (\%) } & $36 \%$ & $30 \%$ & $25 \%$ & $23 \%$ & $13 \%$ \\
\hline & \multicolumn{5}{|c|}{ Taxa de Desconto: 7\% } \\
\hline VPCT Público & $115.995,36$ & $168.460,96$ & $136.990,72$ & $181.867,15$ & $282.940,27$ \\
\hline VPCT Privado & $92.900,86$ & $139.478,80$ & $117.207,31$ & $160.402,94$ & $276.796,79$ \\
\hline Diferencial (R\$) & $23.094,49$ & $28.982,16$ & $19.783,41$ & $21.464,21$ & $6.143,47$ \\
\hline Diferencial (\%) & $25 \%$ & $21 \%$ & $17 \%$ & $13 \%$ & $2 \%$ \\
\hline
\end{tabular}




\subsubsection{Valor Presente do Contrato de Trabalho dos professores}

De forma oposta ao que ocorre com o diferencial do VPCT oferecido nas redes pública e privada para as mulheres no Brasil, os homens observam diferenciais pró ensino público mais baixos, que chegam a ser negativos no ensino médio. Este resultado diferente entre homens e mulheres decorre principalmente do maior tempo de trabalho necessário para a aposentadoria masculina. Desta forma, a aposentadoria mais elevada não consegue compensar o menor salário recebido durante os anos de trabalho na rede pública. Entretanto, para uma taxa de desconto de 3\% o diferencial em favor da rede pública está entre $18 \%$ e $47 \%$ (Tabela 16). Com uma taxa de desconto mais elevada, $7 \%$, este diferencial cai sobremaneira. O médio é o nível de ensino em que os contratos de trabalho do ensino público são menos vantajosos, com um diferencial desfavorável de $3 \%$ em relação ao setor privado.

TABELA 16 - DIFERENCIAIS DE VPCT - PROFESSORES DAS REDES PÚBLICA E PRIVADA (BRASIL) - VALORES EM R\$ (SET./2000)

\begin{tabular}{|c|c|c|c|c|c|}
\hline & \multicolumn{5}{|c|}{ Nível de ensino } \\
\hline & \multirow[t]{2}{*}{ Pré-Escola } & \multicolumn{2}{|c|}{ Fundamental } & \multirow[t]{2}{*}{ Médio } & \multirow[t]{2}{*}{ Superior } \\
\hline & & Primário & Ginásio & & \\
\hline & \multicolumn{5}{|c|}{ Taxa de Desconto: $3 \%$} \\
\hline VPCT Público & $307.256,73$ & $443.910,20$ & $289.675,69$ & $541.004,09$ & $935.358,25$ \\
\hline VPCT Privado & $209.214,04$ & $319.782,41$ & $219.019,71$ & $428.347,07$ & $790.688,16$ \\
\hline Diferencial (R\$) & $98.042,69$ & $124.127,79$ & $70.655,98$ & $112.657,02$ & $144.670,10$ \\
\hline \multirow[t]{2}{*}{ Diferencial (\%) } & $47 \%$ & $39 \%$ & $32 \%$ & $26 \%$ & $18 \%$ \\
\hline & \multicolumn{5}{|c|}{ Taxa de Desconto: $5 \%$} \\
\hline VPCT Público & $185.053,81$ & $261.091,12$ & $168.981,55$ & $318.941,06$ & $556.502,00$ \\
\hline VPCT Privado & $142.494,88$ & $215.033,38$ & $147.993,24$ & $294.037,08$ & $515.430,51$ \\
\hline Diferencial (R\$) & $42.558,93$ & $46.057,74$ & $20.988,31$ & $24.903,98$ & $41.071,48$ \\
\hline \multirow[t]{2}{*}{ Diferencial (\%) } & $30 \%$ & $21 \%$ & $14 \%$ & $8 \%$ & $8 \%$ \\
\hline & \multicolumn{5}{|c|}{ Taxa de Desconto: 7\% } \\
\hline VPCT Público & $121.393,83$ & $170.607,19$ & $109.614,45$ & $208.723,60$ & $358.451,44$ \\
\hline VPCT Privado & $103.811,47$ & $154.485,20$ & $106.934,49$ & $214.543,41$ & $354.639,22$ \\
\hline Diferencial (R\$) & $17.582,35$ & $16.122,00$ & $2.679,96$ & $-5.819,81$ & $3.812,22$ \\
\hline Diferencial (\%) & $17 \%$ & $10 \%$ & $3 \%$ & $-3 \%$ & $1 \%$ \\
\hline
\end{tabular}


Os resultados da Tabela 17 mostram que o contrato de trabalho oferecido em São Paulo apresenta um valor superior ao resto do País. Assim como ocorre no Brasil, o secundário apresenta os diferenciais mais baixos em favor da rede pública. Diferentemente do que ocorre com o Brasil, em São Paulo nenhum VPCT favorece a rede privada. Os diferenciais em favor da rede pública de ensino são pelo menos 5\% maiores para a rede pública, quando se utiliza uma taxa de desconto de $7 \%$.

\section{TABELA 17 - DIFERENCIAIS DE VPCT - PROFESSORES DAS REDES PÚBLI- CA E PRIVADA (SÃO PAULO) - VALORES EM R\$ (SET./2000)}

\begin{tabular}{|c|c|c|c|c|c|}
\hline & \multicolumn{5}{|c|}{ Nível de ensino } \\
\hline & \multirow[t]{2}{*}{ Pré-Escola } & \multicolumn{2}{|c|}{ Fundamental } & \multirow[t]{2}{*}{ Médio } & \multirow[t]{2}{*}{ Superior } \\
\hline & & Primário & Ginásio & & \\
\hline & \multicolumn{5}{|c|}{ Taxa de Desconto: $3 \%$} \\
\hline VPCT Público & $311.774,16$ & $608.172,61$ & $512.213,18$ & $656.413,90$ & $1.108 .992,90$ \\
\hline VPCT Privado & $199.246,94$ & $419.569,80$ & $360.501,74$ & $491.053,22$ & $856.805,37$ \\
\hline Diferencial $(\mathrm{R} \$)$ & $112.527,22$ & $188.602,80$ & $151.711,44$ & $165.360,68$ & $252.187,53$ \\
\hline \multirow[t]{2}{*}{ Diferencial (\%) } & $56 \%$ & $45 \%$ & $42 \%$ & $34 \%$ & $29 \%$ \\
\hline & \multicolumn{5}{|c|}{ Taxa de Desconto: $5 \%$} \\
\hline VPCT Público & $202.420,50$ & $361.483,22$ & $305.554,64$ & $393.601,03$ & $655.753,55$ \\
\hline VPCT Privado & $134.550,89$ & $288.199,81$ & $247.573,20$ & $339.777,70$ & $549.035,98$ \\
\hline Diferencial $(\mathrm{R} \$)$ & $67.869,61$ & $73.283,41$ & $57.981,45$ & $53.823,33$ & $106.717,56$ \\
\hline \multirow[t]{2}{*}{ Diferencial (\%) } & $50 \%$ & $25 \%$ & $23 \%$ & $16 \%$ & $19 \%$ \\
\hline & \multicolumn{5}{|c|}{ Taxa de Desconto: 7\% } \\
\hline VPCT Público & $141.810,07$ & $239.034,78$ & $202.565,75$ & $262.742,09$ & $421.023,22$ \\
\hline VPCT Privado & $97.439,55$ & $209.796,09$ & $181.539,91$ & $249.046,85$ & $370.487,04$ \\
\hline Diferencial $(\mathrm{R} \$)$ & $44.370,52$ & $29.238,69$ & $21.025,84$ & $13.695,24$ & $50.536,18$ \\
\hline Diferencial (\%) & $46 \%$ & $14 \%$ & $12 \%$ & $5 \%$ & $14 \%$ \\
\hline
\end{tabular}

Esta seção mostrou que os professores na rede pública de ensino não recebem um contrato inferior ao pago na rede privada. Ou seja, salvo o ensino secundário, os outros níveis de ensino público pagam contratos superiores ao da rede privada de ensino. No nível médio, dependendo da taxa de desconto, os contratos públicos podem ser inferiores àqueles oferecidos pela rede privada. Este fato pode ajudar a explicar a grande carência de professores no secundário. 


\section{UMA FORMA ALTERNATIVA DE APRESENTAR OS RESULTADOS: CÁL- CULO DAS TAXAS INTERNAS DE RETORNO (TIRS) DO SISTEMA PREVI- DENCIÁRIO}

Nesta seção, os diferenciais de remuneração dos professores das redes pública e privada são quantificados e apresentados de uma maneira alternativa. Ao invés de computar o Valor Presente do Contrato de Trabalho (VPCT) com base nas taxas de desconto, faz-se aqui o cálculo da Taxa Interna de Retorno (TIR) do sistema previdenciário. Por definição, a TIR é a taxa que iguala os valores presentes esperados dos fluxos de contribuições feitas e benefícios recebidos ao longo da vida dos indivíduos de cada categoria profissional. Para o cômputo da TIR dos sistemas previdenciários público e privado é necessário calcular as contribuições e os benefícios, por nível de ensino. Na equação (4) (similar à equação 3 apresentada anteriormente), a TIR é dada pela variável $r$. O termo do lado esquerdo representa o valor presente das contribuições e o termo do lado direito o valor presente dos benefícios.

$$
\sum_{j=o}^{A-1} \frac{w_{k j} \tau_{j}}{(1+r)^{j}}=\sum_{j=A}^{T} \frac{b_{k j}}{(1+r)^{j}}
$$

Assim como adotado nas seções anteriores, faz-se a hipótese de que os professores de ambas as redes de ensino se aposentam assim que cumprem os requisitos mínimos necessários para a obtenção do benefício. Implicitamente, há uma suposição de estabilidade ocupacional. Ou seja, que os professores não migram do emprego público para o emprego privado e vice-versa ao longo de sua vida ativa. A Tabela 18 apresenta as TIRs por gênero e rede de ensino.

Como já era esperado, tendo em vista os resultados das seções anteriores, nota-se a existência de um nítido diferencial pró-docentes do setor público. Com exceção de três casos, as TIRs desse grupo sempre apresentam dois dígitos. Esses valores elevados contrastam nitidamente com as TIRs do setor privado, cujo maior valor é de 4,2\% para os homens que lecionam no ensino fundamental (ginásio) no Brasil. Em três casos (para os docentes no ensino superior) as TIRs chegam a ser negativas. A diferença entre as TIRs está na faixa entre 8,7 e 11,4 pontos percentuais, o que é bastante expressivo. Também é possível constatar que, comparando as TIRs calculadas para São Paulo com aquelas calculadas para o Brasil, pode-se perceber que a TIR das mulheres é similar, enquanto a dos homens é mais elevada no Brasil do que em São Paulo. Note-se que os valores aqui encontrados são bastante similares àqueles encontrados por Caetano (2006), em que pesem as diferenças metodológicas dos dois estudos. 
TABELA 18 - TAXAS INTERNAS DE RETORNO (TIR) DO SISTEMA PREVIDENCIÁRIO - PROFESSORES DAS REDES PÚBLICA E PRIVADA - (VALORES EM \%)

\begin{tabular}{|c|c|c|c|c|c|c|}
\hline & \multirow{3}{*}{ Gênero } & \multicolumn{5}{|c|}{ Nível de ensino } \\
\hline & & \multirow[t]{2}{*}{ Pré-Escola } & \multicolumn{2}{|c|}{ Fundamental } & \multirow[t]{2}{*}{ Médio } & \multirow[t]{2}{*}{ Superior } \\
\hline & & & Primário & Ginásio & & \\
\hline \multicolumn{7}{|c|}{ Brasil } \\
\hline \multirow{2}{*}{ Setor Público (a) } & Mulher & 13,6 & 13,7 & 13,8 & 14,1 & 9,7 \\
\hline & Homem & 13,6 & 12,7 & 12,9 & 12,7 & 7,6 \\
\hline \multirow{2}{*}{ Setor Privado (b) } & Mulher & 2,2 & 3,4 & 3,6 & 3,4 & 0,1 \\
\hline & Homem & 2,5 & 4,2 & 4,2 & 3,3 & $-1,1$ \\
\hline \multirow{2}{*}{ Diferencial (a-b) } & Mulher & 11,4 & 10,3 & 10,2 & 10,7 & 9,6 \\
\hline & Homem & 11,1 & 8,6 & 8,7 & 9,3 & 8,7 \\
\hline \multicolumn{7}{|c|}{ São Paulo } \\
\hline \multirow{2}{*}{ Setor Público (a) } & Mulher & 13,4 & 13,3 & 13,3 & 13,6 & 10,2 \\
\hline & Homem & 11,0 & 12,4 & 12,3 & 12,2 & 7,9 \\
\hline \multirow{2}{*}{ Setor Privado (b) } & Mulher & 2,0 & 3,3 & 3,5 & 3,3 & $-0,1$ \\
\hline & Homem & 1,8 & 3,5 & 3,6 & 2,9 & $-1,4$ \\
\hline \multirow{2}{*}{ Diferencial (a-b) } & Mulher & 11,4 & 10,0 & 9,8 & 10,3 & 10,3 \\
\hline & Homem & 9,2 & 8,9 & 8,7 & 9,3 & 9,3 \\
\hline
\end{tabular}

As diferenças entre os setores público e privado parecem ser motivadas por duas causas principais. A primeira refere-se à regra de cálculo das contribuições e dos benefícios do setor privado. Diferentemente do que ocorre para os benefícios, não há teto contributivo para os empregadores. Desta maneira, a contribuição patronal (que representa cerca de dois terços do total) incide sobre toda a remuneração do professor, onerando mais aqueles com remuneração mais elevada. A segunda causa é a existência da paridade entre ativos e inativos do setor público. Outro aspecto que deve ser ressaltado, com base nos dados da tabela acima, é o fato de as TIRs de homens e mulheres serem próximas. Como as mulheres se aposentam com cinco anos a menos de contribuição, esperava-se que estas tivessem uma TIR superior à dos homens. Entretanto, os resultados, de forma um tanto quanto surpreendente, não confirmam esta hipótese.

Para os professores do ensino fundamental da rede privada (que recebem salários inferiores ao teto previdenciário) o retorno dos homens é superior ao das mulheres 
para o Brasil. A partir do ensino médio esta tendência se inverte e as professoras obtêm uma TIR maior. Analisando os dados de São Paulo, onde os salários médios são superiores à média do Brasil, praticamente não há diferença nas TIRs por gênero no fundamental. Já no ensino médio, a diferença é favorável às mulheres. No setor público, diferentemente do setor privado, as TIRs de homens e mulheres são próximas, com estas recebendo taxas de retorno superiores em não mais do que dois pontos percentuais em relação aos homens. Como os benefícios recebidos tanto no setor público como no privado são diretamente relacionados aos últimos salários, e os salários crescem com o tempo de serviço, os benefícios dos que se aposentam posteriormente são superiores aos dos que se aposentam antes, e os resultados mostram que esta elevação dos benefícios parece compensar o maior tempo de contribuição.

Assim, esta seção mostrou que um dos grandes benefícios do setor público em relação ao privado é o benefício previdenciário, que pode ser entendido com uma aplicação financeira, com uma taxa interna de retorno muito superior àquela que pode ser obtida no setor privado. $\mathrm{O}$ diferencial de retorno, favorável à rede pública, varia entre 9,7 e 11,6 pontos percentuais para as professoras e entre 8,7 e 11,3 pontos percentuais para os professores. Por último, conclui-se que a possibilidade de a mulher se aposentar cinco anos antes que o homem não apresenta grande vantagem em termos de taxa interna de retorno. ${ }^{9}$

\section{COMENTÁRIOS FINAIS}

Podemos concluir que, de forma distinta do que tem sido defendido em alguns debates, não se pode afirmar que os diferenciais salariais favorecem os professores da rede privada. Entre os anos de 1980 e 2000, nota-se uma perda salarial relativa dos professores do setor público. Esta perda é maior em alguns Estados. No entanto, não se nota um padrão específico de perda por Estado, para todos os níveis de ensino. Esta não-regularidade nos resultados nos leva a inferir que não há nenhuma política educacional consistente para elevar a remuneração dos professores.

Entretanto, apesar de haver Estados em que professores de níveis de ensino distintos ganham salários diferentes aos pagos na rede privada, observa-se uma convergência entre os diferenciais de salário pagos no Brasil. Entre 1980 e 2000, o país observou uma redução na variância dos diferenciais de salários entre os Estados. Esta redução aproximou os salários públicos dos privados em grande parte dos Estados, reduzindo

9 Embora a TIR feminina não seja substancialmente superior à masculina, a aposentadoria precoce da mulher onera as finanças públicas, pois além do menor período contributivo, a expectativa de vida feminina é maior. 
o ganho dos que recebem um diferencial positivo e a perda daqueles que recebem um salário público inferior ao privado.

As conclusões mudam quando é calculado o VPCT. Percebe-se que os contratos oferecidos na rede pública são consistentemente melhores do que os oferecidos na rede privada. Ou seja, a diferença de regras no sistema previdenciário é um importante fator no cômputo da renda recebida ao longo da vida. Desta foram, as aposentadorias recebidas pelos docentes da rede pública parecem ser um importante incentivo a que estes não escolham a rede privada para trabalhar. Estes resultados foram corroborados pelos resultados das TIRs. Se a previdência social for entendida como uma espécie de aplicação financeira, então a previdência dos docentes da rede pública configura-se como um ótimo negócio, dadas as elevadas taxas de retorno encontradas.

\section{REFERENCIAS}

AFONSO, L. E.; FERNANDES, R. Uma estimativa dos aspectos distributivos da previdência social no Brasil. Revista Brasileira de Economia. v. 59, n. 3, 2005.

ALÉM, A. C.; PASTORIZA, F.; GIAMBIAGI, F. A aposentadoria por tempo de serviço no Brasil: estimativa do subsídio recebido pelos seus beneficiários. Revista Brasileira de Economia, v. 52, n.1, 1998.

ARVATE, P.R.; MARCONI, N.; MORICONI, G. M.; MOURA-NETO, J. S. Diferentes padrões de políticas salariais nos governos estaduais brasileiros: uma análise a partir do diferencial de salários público-privado. In: XXX ENANPAD, 2006, Salvador. Anais do XXX Encontro da Anpad. Salvador: EnAnpad, 2006.

BARROS, R.P.; FOGUEL, M.N.; Gill, I. Mendonça, R. The public-private wage gap in Brazil. Revista Brasileira de Economia, v. 54, n. 4, 2000.

BENDER, S.; FERNANDES, R. Gastos públicos com pessoal: uma análise de emprego e salário no setor público brasileiro no período 1992-2004. In: XXXIV ENCONTRO NACIONAL DE ECONOMIA, 2006. Anais do XXXIV Encontro Nacional de Economia da Anpec. Salvador, 2006.

BORJAS, George J. Labor Economics. Boston: McGraw-Hill/Irwin, 2005.

CAETANO, M. A. R. Subsídios cruzados na previdência social brasileira. Ipea, 2006 (Texto para Discussão, n. 1211).

COELHO, A. M.; C. H. Desigualdades salariais no Brasil: um breve panorama. In: CORSEUIL, C. H. (Ed.). Estrutura salarial: aspectos conceituais e novos resultados para o Brasil. Rio de Janeiro: Ipea, 2002.

EHRENBERG, R.G.; SCHWARZ, J.L. Public sector labor markets. In: ASHENFELTER, O.C.; LAYARD, R. Handbook of Labor Economics, v. 2, 1986. 
EHRENBERG, Ronald G; SMITH, Robert S. Modern labor economics. Nova York: Harper Collins, 1994.

FELDSTEIN, M. Social security, induced retirement and aggregate capital accumulation. Journal of Political Economy, v. 82, n. 5, 1974.

FERNANDES, R. Desigualdade salarial: aspectos teóricos. In: CORSEUIL, C. H. (Ed.). Estrutura salarial: aspectos conceituais e novos resultados para o Brasil. Rio de Janeiro: Ipea, 2002.

FOGUEL, M. N.; GILL, I.; MENDONÇA, R.; PAES DE BARROS, R. The publicprivate wage gap in Brazil. Revista Brasileira de Economia, v. 54, n. 4, 2000.

GOMES, C. A. A escola de qualidade para todos: abrindo as camadas da cebola. Ensaio: Avaliação e Politicas Públicas em Educação, v. 13, n. 48, 2005.

GREGORY, R.G.; BORLAND, J. Recent developments in public sector labor markets. In: Ashenfelter, O.C.; Card. D. (Ed.). Handbook of Labor Economics, v. 3, 1999.

KATZ, L.F; KRUEGER, A.B. Changes in the structure of wages in the public and private sectors. In: EHRENBERG, R. (Ed.). Research in Labor Economics, 12, p. 131-172, 1991.

KRAWCZYK, N. A escola média: um espaço sem consenso. Cadernos de Pesquisa, n. 120 , nov. 2003.

MARCONI, N. Gap between public and private wages and wages determination in the public sector. Revista de Economia Politica. vol. 24, n. 2, 2004.

MINCER, J. Investment in human capital and personal income distribution. Journal of Political Economy, v. 66, n. 4, 1958.

MORICONI, G. M. Todos os servidores públicos são bem remunerados? Uma comparação entre as carreiras do setor público brasileiro. In: XXXI ENANPAD, 2007, Rio de Janeiro. Anais do XXXI Encontro da Anpad. Rio de Janeiro: EnAnpad, 2007.

PAES DE BARROS, R.; MENDONÇA, R.; BLANCO, M. O mercado de trabalho para professores no Brasil. In: XXIX ENCONTRO NACIONAL DE ECONOMIA, 2001, Salvador. Anais do XXIX Encontro Nacional de Economia da Anpec. Salvador, 2001.

POTERBA, J.; RUEBEN, K. Fiscal institutions and public sector labor market. NBER Working paper n. 6659, 1998.

RAMALHO, M.; URANI, A. A administração pública como empregadora: uma avaliação da década de 80. Rio de janeiro: Ipea, abril 1995. 22 p. (Série Seminários, n. $5 / 95)$.

. A administração pública como empregadora: uma avaliação da década de 80. In: XXIII ENCONTRO NACIONAL DE ECONOMIA, 2001, Salvador. Anais do XXIII Encontro Nacional de Economia da Anpec. Salvador, 2001. 